\title{
Ultrastructure features of spermiogenesis and spermatozoa of sparid fish Rhabdosargus sarba (Forsskål, 1775) from Red SEA, Jeddah coast
}

\author{
S.G. Moharram*, S. A. Qari ${ }^{\mathrm{a}}$ and S. A. El-Aweedy \\ Department of Biology, Faculty of Science, King Abdulaziz University, Jeddah, Saudi Arabia
}

\begin{abstract}
Transmission and scanning electron microscopy were used to investigate the ultrastructure of spermatogenesis of the Sparid fish Rhabdosargus sarba. The testis is lobular in shape and spermatogensis is of unrestricted type. Spermatogonia occur isolated or in clusters within the seminiferous lobules. The germ cells are found in cysts formed by sertoli cell processes. Cells within cysts are found in the same developmental stage. Spermiogenesis is characterized by chromatin condensation, movement of the centrioles, flagellum development, nuclear rotation, nuclear indentation and nuclear fossa formation, reduction of the cytoplasm and differentiation of the flagellar complex. Ultrastructurally the spermatozoa of R. sarb belonges, like that of other sparid fish, to the teleosean "type 1" spermatozoan with the flagellum axis perpendicular to the nuclear fossa. It has an ovoidal head, a short, cylindrically shaped midpiece and a long tail region. The nucleus reveals a deep invagination (nuclear fossa) in which the centrriolar complex is located, and a satellite nuclear noch shaped like a bell. The centriolar complex lies inside the nuclear fossa and is composed of a proximal and a distal centriole. The two centerioles are perpendicular to each other. The distal centriole is traversed by a conspicuous basal plate in its base. At the neck of the flagellum the necklace is observed.

A nuclear noch is located above the proximal centeriol. The short midpiece houses two spherical mitochondria. The flagellum is inserted medio-laterally into the head, contains the conventional 9+2 axoneme.
\end{abstract}

Keywords: sperm ultrastructurey; Rhabdosargus sarb; Sparidae;

\section{Introduction}

Family Sparidae is one of the most important economically fish species in the Red Sea. The sparids are also considered one of the most diversified families as far as the expression of sexuality is concerned. Sparids are characterized by a rudimentary type of hermaphroditism with a low level of protandry and a multiple spawning character (Pajuelo et al., 2008).

Within the family Sparidae, sperm ultrastructure has been investigated in all subfamilies except Denticinae. In particular investigated sparids are Pagrus major (Gow et al, 2004), Acantopagrus australis and A.berda (Gow et al,2005); Boops boops ( Zaki et al., 2005); Sparus aurata (Maricchiolo et al., 2007); Diplodus cervinus (Jamieson, 2009) and Pagellus bagaraveo (Maricchiolo et al., 2010).

All these species have a uniflagellate anacrosomal aquqsperm, as is typically found in external fertilization fishes (Jamieson, 1991), and share some ultrastructural features, such as the location of the centeriolar complex inside the nuclear fossa and the pendicular insertion of the flagellum with respect to the nucleus.

The present paper provides a description of the ultrastructure of spermatogenic stages and the mature spermatozoan of $R$.sarpa belonging to family Sparidae and to compare it with those available on other fish groups to assess the phylogenetic relationship with other teleosts.

\section{Material and methods}

In February, during the breeding season (December to March), adult $R$. sarba (Perciformes, Sparidae) (400-500 g body weight) were transformed to the laboratory. The male fishes were judged to be mature when semen could be hand stripped from urinogenital opening. Testis fragments were fixed in in $2 \%$ gutaraldehyde in $0.2 \mathrm{M}$ sodium cacodylate buffer $\mathrm{pH} 7.2$ for $1 \mathrm{~h}$. at $4^{\circ} \mathrm{C}$ and post-fixed in $1 \%$ osmium tetroxide in the same buffer for $1 \mathrm{~h}$. The samples were dehydrated in a graded ethyl alcohol series and embedded in epoxy resins Sections were made on an JEOL JUM-7 ultramicrotome with glass knifes and stained with $1 \%$ toluidine bluein $1 \%$ sodium borate. The sections were stained with uranyl acetate (saturated in $70 \%$ ethyl alcohol) followed by lead citrate and examined with PHILIPS CM 100 transmission electron microscope at $60 \mathrm{kV}$ voltage at King Fahd Medical Research Center (Electron Microscope Unite) .

For scanning electron microscopy (SEM) samples were fixed in Trump's fixative from half to one hour , after which samples were rinsed three times in distilled water (10 min each), fixed in Osmium Tetroxide (1 hour), rinsed twice in distilled water (1min each) , $50 \%$ Ethanol 1 main , $100 \%$ Ethanol (10 min), ethanol : 
acetone (1:1) for 10 minute, pure acetone three changes (10 minutes each), Acetone: Hexamethyldisilazane (1:1) for one hour, pure Hexamethyldisilazane also one hour and remove the Hexamethyldisilazane and was put the sample under vacuum (10 min (H.P) or overnight (L.P) then critical -point dried and gold coated. Preparation were viewed in a QUANTA 250 SEM at King Fahd Medical Research Center ( Electron Microscopy Unite).

\section{Ultrastructure of testes of R.sarba.}

\section{Results}

Based on morphological characteristics and the development of germ cells in the seminiferous tubules of the testis, spermatogenesis were classified into 4 successive stages: (1) spermatogonium, (2) spermatocyte, (3) spermatid, and (4) spermatozoon stages (Fig.1 \& 2).

\section{Spermatogonium stage.}

Spermatogenesis occurred in cysts of the seminiferous tubules. Primary spermatogonia (approximately 6.7-10.33 $\mu \mathrm{m}$ with average of $8.2 \mu \mathrm{m}$ in diameter) were the largest germ cells in the testis, and were present throughout the year. These cells were slightly oval or spherical in shape, and a single prominent nucleus the contained a single nucleolus. Chromatin materials in the nucleus were frequently observed in different degrees of condensation according to the mitotic stage. The primary spermatogonium divided mitotically to produce secondary spermatogonia. Secondary spermatogonia (approximately 4.3 to $7.4 \mu \mathrm{m}$ with average of $5.5 \mu \mathrm{m}$ in diameter) were characterized by a decreased cell size compared to primary spermatogonia (Fig .2).

\section{Spermatocyte stage.}

Primary spermatocytes arose from the mitotic division of secondary spermatogonia. Primary spermatocytes (approximately 2.6 to $5.6 \mu \mathrm{m}$ with average of $3.6 \mu \mathrm{m}$ in diameter) were oval-shaped, and it was sometimes hard to distinguish the cellular limits. The nucleus of the primary spermatocyte contained chromatin which was slightly denser than that of the secondary spermatogonium. At this stage, the nucleolus was not visible, and chromosomic masses (referred to as synaptonemal complexes) were frequently found (Fig. 1 \& 2).

\section{Spermatid stage.}

Secondary spermatocytes gave rise to spermatids through the 2nd meiotic division. Spermatids were seen in different stages of spermiogenesis, as indicated by the degree of chromatin condensation. Spermatids underwent a shape re-modeling and a size reduction during spermiogenesis. In the early part of the spermatid stage (approximately 1.4 to $1.8 \mu \mathrm{m}$ with average of $1.5 \mu \mathrm{m}$ in diameter), nuclei were oval or rounded, and became smaller as the chromatin condensed. At this stage, in particular, condensation of electrondense heterochromatin masses appeared in the nucleus (Fig. 3B). During spermiogenesis, the morphology of the spermatid nucleus gradually changed, and several mitochondria and a centrosome moved to a position just behind the nucleus of the spermatid (Fig. $3 \mathrm{C}$ ).

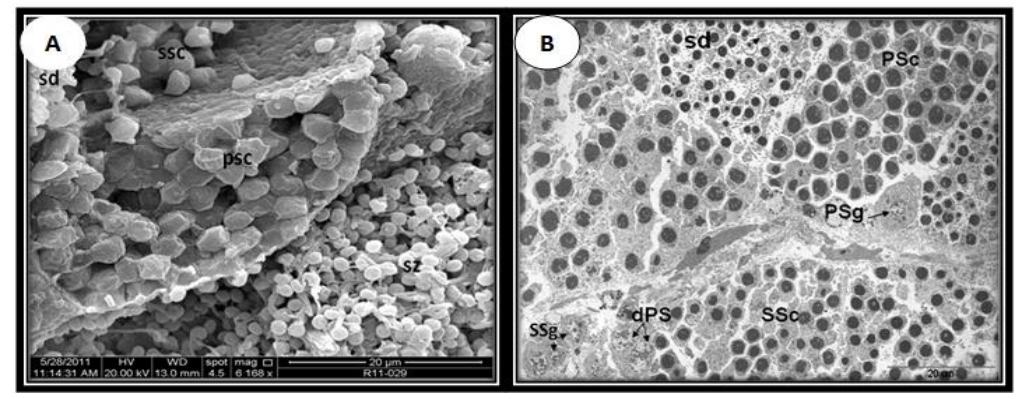

Figure (1).: A: Scanning electron micrographs of $R$. sarba of ripe testes showing Primary Spermatocyte; Secondary Spermatocyte; spermatid; Spermatozoa in lumen of the testes lobules. B: Transmission electron micrographs (TEM) Cross section of the seminiferous tubules revealed the 'lobular' type. Each lobule consists of several cysts contains groups of developing germ i.e., Primary spermatogonium (PSg); Secondary spermatogonium (SSg); Primary spermatocyte (PSc); Secondary spermatocyte (SSc); spermatid (sd); Sz: Spermatozoa \& division of the Primary spermatogonium (dPSg).

In the late stage of spermiogenesis, the final spermatids were still in the cysts. At this time, two centrioles were initially located near the nuclear envelope; the proximal centriole appeared near the nuclear envelope, and the distal centriole formed the basal body of the flagellum. The basal body gave rise to a 
flagellum. A flagellum formed from each centriole prior to the mitochondrial arrangement in the region that would become the midpiece (Fig.3C).

\section{Spermatozoon stage:}

In this stage, the differentiation of spermatozoa was completed, and the heads of these spermatozoa were created at the periphery of the cysts toward the lumen of seminiferous tubules, with their tails oriented in the opposite direction.

The spermatozoon of R. sarba is auniflagellate cell, differentiated head, a short midpiece, and along cylindrical tail (Fig4 A\&B). The head is ovoid with the lateral axis greater than longitudianal axis.

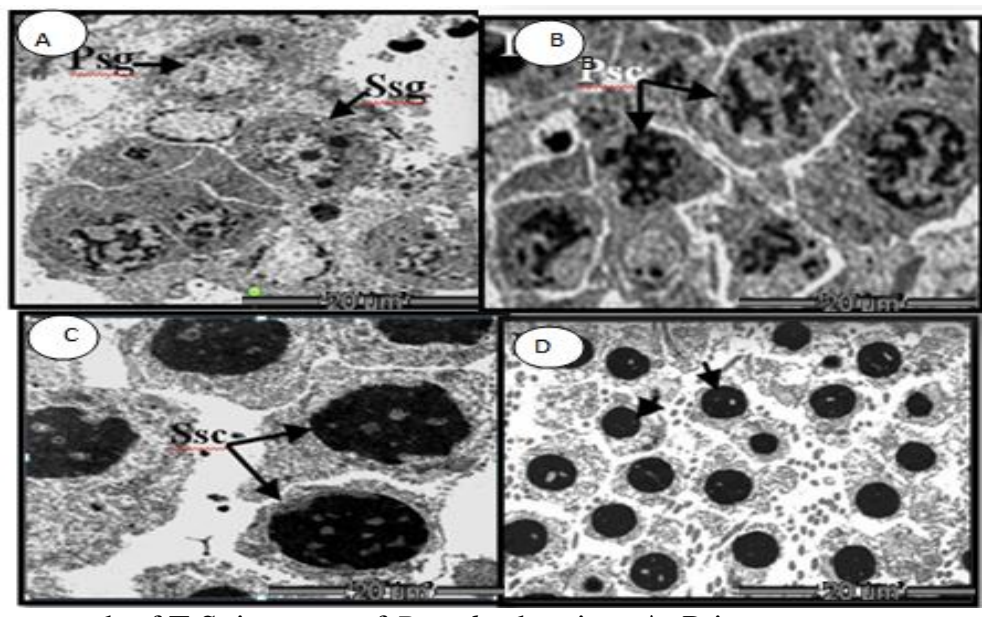

Figure (2). Electromicrograph of T.S. in testes of R.sarbashowing: A, Primary

(Pssg) and secondary (Ssg) spermatogonia; B, Primary spermatocytes

(Psc); C,Secondary spermatocytes (Ssc); D, Spermatids (Arrow head).

The nucleus showed a homogenous, electron-dense chromatin compact in texture. At the base of the nucleus, the nuclear envelope invaginated, forming a deep depression ,called the nuclear fossa, containing the centriolar complex .The nuclear fossa appeared deep and bell-shaped in a sagittal longitudinal section. It appeared smaller at the apical end and enlarged posteriorly (Fig.5A). The anterior region of the nuclear fossa was occupied by the proximal centriole, whereas the distal centriole (which serves as the basal body of the flagellum ) was located in the posterior region (Fig. 5 A\&B).

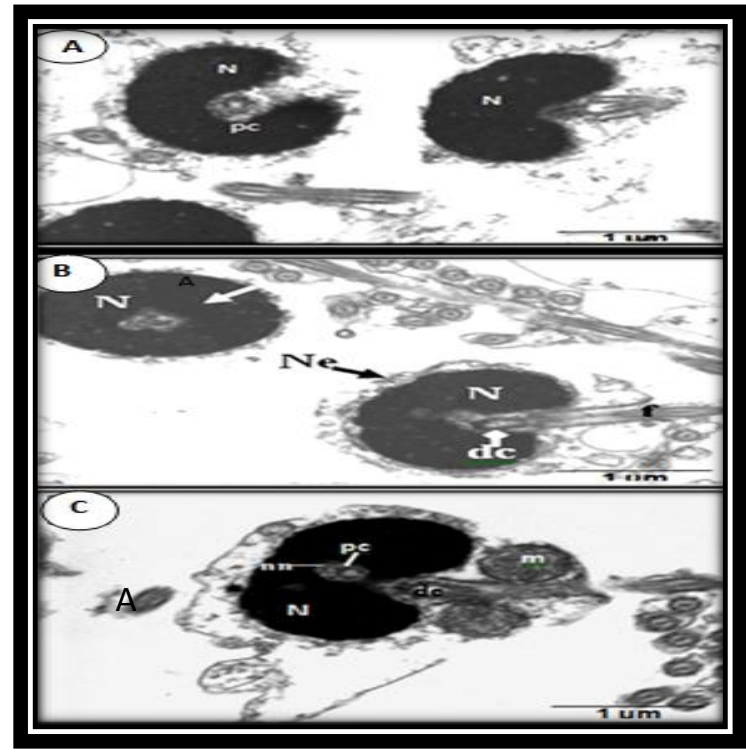

1. Figure(3): Transmission electron micrographs (TEM) of R. sarba spermatids at different stage of spermiogenesis. A. Spermatid during spermiogenesis. B. Early and late spermatid stages. C. Spermatid in the late stage of spermiogenesis. nuclear notch $(\mathrm{nn})$; proximal centriole $(\mathrm{pc})$; nucleus $(\mathrm{N})$; distal centeriol $(\mathrm{dc})$ mitochondria (m); flagellum (f); nuclear envelope (Ne). 
A peculiar satellite nuclear notch shaped like a v-shaped (Fig.5D) was visible in cross-section, originating from the nuclear fossa, at the level of the distal centriole. Some electron -dense material occured inside the notch. The two centrioles were hollow , cylindrical structures with the conventional 9+0 microtubular pattern. The proximal centeriol was anterior and slightly oblique in relation to the distal centeriol, at the posterior end, the distal centriole was traversed by a basal plate.

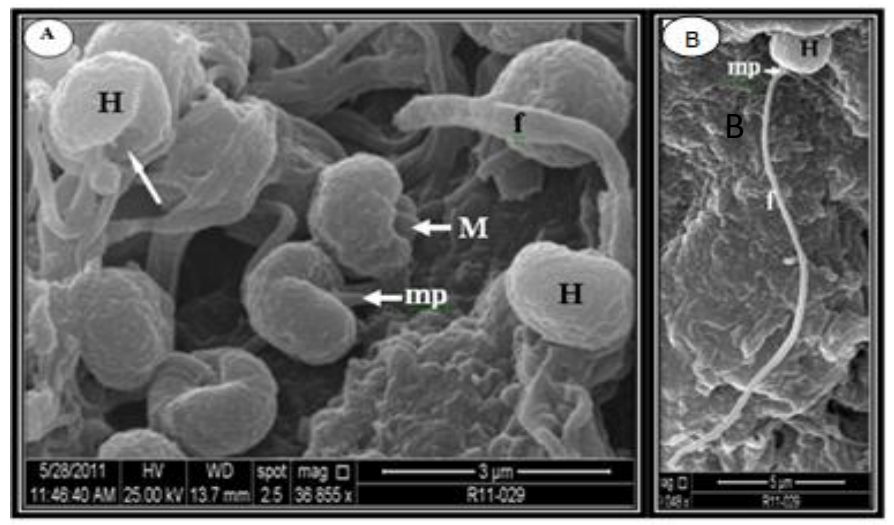

Figure 4: Scanning electron micrographs of $R$. sarba spermatozoa. A: showing head (H); mitochondria (M); midpiece (mp) and flagellum (f). There is an obvious invagination at the posterior pole of the sperm head, with exterior surface smoothly curving inward to the central interior cavity (arrow). B: Whole view of $R$. sarba spermatozoa showing the head $(\mathrm{H})$; midpiece $(\mathrm{mp})$ and flagellum (f).

The midpiece was short and cylindrical in shape (Fig.4 A\&B) and contained numerous electron-clear vesicles in the cytoplasm. Two spherical mitochondrion (average $0.4 \pm 0.1 \mu \mathrm{m}$ in diameter) can be seen in the midpiece region (Fig. 4. A).

The mitochondrion contained an electrons-dense matrix and has irregularly arranged cristae; it is separated from by an invagination of the plasma membrane. A second membrane is located underneath the invaginated portion of the plasmalemma extending along the cytoplasmic canal (Fig 4 \& 5B).

The flagellum, which has a cylindrical shape throughout its length, measures $12.9 \mathrm{um}$ and is inserted perpendicularly and eccentrically with respect to lateral and longitudinal axis of ovoid nucleus (Fig. 4B \& 5D). The axoneme showed a typical eukaryotic organization, consisting of nine outer doublet microtubules and a central pair of singlet microtubules $9+2$ pattern (Fig. 6).

The electron-dense particles, termed the necklace, were observed in the plasma membrane surrounding the neck of the flagellum (Fig. 5B).

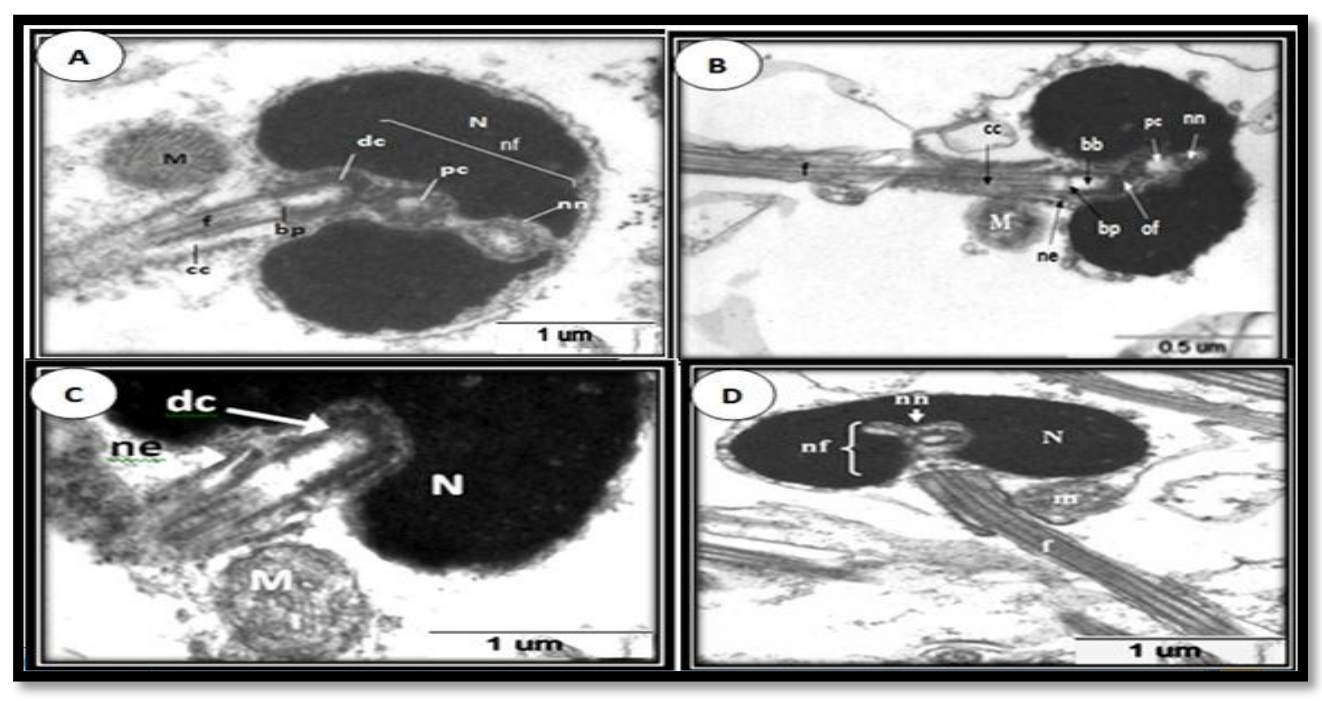

Figure 5: Transmission electron micrographs (TEM) of the sperm head showing: A; nuclear notch (nn) lies on the top of the proximal centriole (pc) and the bell-shape of nuclear fosaa (nf). B: The distal centriole is traversed by a conspicuous basal plate (bp) in its base. Some electron-dense material is visible inside the notch. Electrondense filaments (of) connect the pair of centrioles. nucleus (N) ; distal centeriol (dc) ; basal plate (bp); mitochondria (M) and flagellum (f) ; cytoplasmic canal (cc). C: The electron-dense particle necklaces (ne, arrow 
head) were observed in the plasma membrane surrounding the neck of the flagellum. D: V-shaped nuclear notch $(\mathrm{nn})$ lies on the top of the proximal centriole (pc).

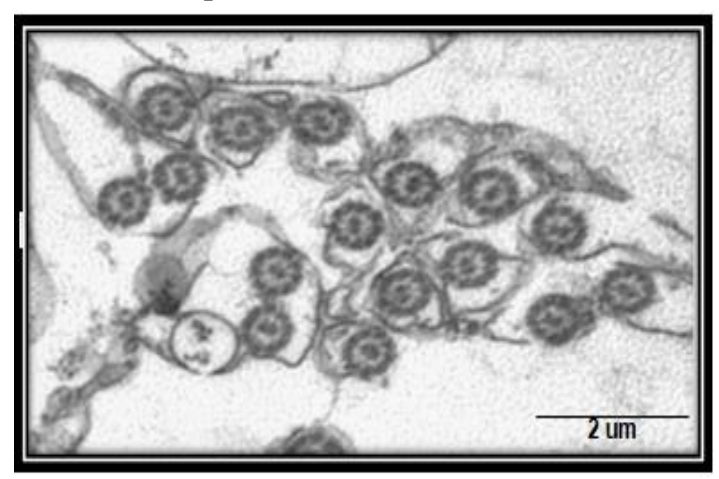

Figure 6 : Transmission electron micrographs (TEM) of the axoneme showing a typical eukaryotic organization, consisting of nine outer doublet microtubules and a central pair of doublet microtubules 9+2 pattern .

\section{Discussion}

Spermatogenesis is a highly organized and coordinated process, in which diploid spermatogonia proliferate and differentiate to form mature spermatozoa. The duration of this process is usually shorter in fish than in mammals and is also influenced by the water temperature (Nõ brega et al., 2009).

The structures of the testis in teleosts are generally divided into unrestricted or restricted spermatogonia-testis type according to the intratubular distribution of spermatogonia (Grier, 1981). In the restricted spermatogonial testis-type the spermatogoina are totally restricted to the distal terminus of the tubule immediately beneath the tunica albuginea where they are associated with Sertoli cells (Grier, 1981). However, in the unrestricted spermatogonial testis-type the distribution of spermatogonia is similar to that observed within the mammalian testis in that they may occur along the entire length of the seminiferous tubule. The spermatogonia are limited to small, peripheral cysts within the tubule which consequently enlarge and extend toward the tubule lumen as spermatogenesis takes place (Grier et al., 1980). The type of testis in R.sarba is unrestricted (Fig. 1A\&B).

The spermatogenesis of R.sarba fish, like the other teleosts, starts from the primary spermatogonia. Primary spermatogonia are thelargest germ cells and possess a prominent nucleolus (Fig. 2 A).

The spermatozoa of the $R$. sarba are of the primitive or ect-aquasperm form and conform to the teleostean type I spermatozoon (Mattel, 1970, Mattei ,1988, 1991). The spermatozoa of $R$. sarba examined in the present study agree with Gwo et al. (2004a). In this study, several unusual features were clarified, the most unique of these is the nuclear notch in the nucleus. A similar structure has been only reported in the spermatozoa of other sparidae A.Schlegeli, A,latus , and pagrus major (Gwo and Gwo , 1993 ; Gwo et al., 1993, 2004a ; Gwo, 1995). Structures, such as necklace, found in the present study, have rarely been reported elsewhere in teleost. Morisawa (2001) also reported 7-10 rows of triangular projections at the base of sperm flagellum of puffer, Takifugu niphobles.

The nuclear notch had been found of six spp. of family sparidae from Pacific ocean. It is likely that this unique character is shared with other sub family Sparinae and may be of systematic in particular through the family Sparidae.

Within the family Sparidae the sperm ultrastructure has been studied in only seven species, B. boops (Mattel, 1970), A. schlegeli (Gwo et al., 1993), A. latus (Gwo, 1995), Diplodus sargus (Lahnsteiner and Patzner, 1995), Diplodus puntazzo (Taddei et al., 2001), P. major (Hara and Okiyama, 1998; Gwo et al.,2004), and R. sarba in the present study.

In the present study, the spermatozoan of $R$. sarba is symmetrical in head region. Similar results also have been recorded in about seven sp. within the family Sparide; A. Schleyeli, (Gwo et al.,1993), A .Latus (Gwo,1995), P.major (Hara and okiyama, 1998).

A common source of interspecific variation in the sperm structure in fishes is the number of mitochondria contained in the midpiece (Baccetti et al., 1984 ; Mattei, 1991) and this holds true for the family Sparidae. Two spherical $0.4 \mu \mathrm{m}$ diameter mitochondrion are present in R.sarba (present study) as in A. australis, L. romboids, three in A. latus and A. berda, four in A. schlegeli and A. probatocephus, One mitochondrion is present in P. bogaraveo, in S. aurata, D. sargus, D. puntazzo, P. erythrinus, B. boops and $P$. major. Mitochondria are responsible for ATP production, the main source of energy for flagellar movement in externally fertilizing fish species (Christen et al., 1987; Cosson et al., 1999).

Structure such as necklace, found in the spermatozoa of $R$. sarba, has also been reported in other species of Sparidae P.major ( Hara and Okiyama ,1998; Gwo et al. , 2004a ) A. australis, A. berda (Gwo et al., 2005), P. 
major, (Gwo et al., 2004a), A. latus (Gwo, 1995) and P. bogaraveo (Maricchiolo et al., 2010) but never been observed in sparids from the Western hemisphere (Gwo et al., 2005).

Quagio-Grassiotto et al.(2003) pointed out that the position of the centriolar complex is related to the shape of the nuclear fossa. So, when the nuclear fossa is deep, the centriolar complex is located inside it .If the nuclear fossa is of the moderate type, it may contain the entire centriolar complex or part of it, or only one of the centrioles, while the other one lies outside. However, if it is completely absent, the centriolar complex usually lies close to the nucleus (Shahin, $2006 \mathrm{a \& b}$ ).

The arrangement of the centriolar complex is variable among teleosts and it is considered a speciesspecific feature (Mansour et al., 2002). The proximal centriole may be anterior or lateral to the distal centriole . In either case, it may be coaxial, parallel, oblique or perpendicular to the distal centriole. In $R$. sarba the two centrioles were arranged perpendicular to each other and the proximal centriole lies anterior to the distal centriole. This is consistent with the cases described in Acanthopagrus Schlegeli (Gwo and Gwo, 1993; Gwo et al., 1993) Acanthopagrus latus (Gwo, 1995), Merluccius merluccius (Medina et al., 2003) and Alestes dentex (Shahin , 2006a).

I $\mathrm{n}$ the sparids, the proximal and distal centrioles lie within the nuclear fossa and are oriented at right angle to each other (Gwo et al., 2005).

In $R$. sarba, the midpiece is located at the posterior end of the nucleus. A similar position of the midpiece has been found in many teleosts (Jamieson, 1991 ; Mattei , 1991 ; Quagio-Grassiotto et al., 2001, 2003 ; Shahin , $2006 \mathrm{a} \& b)$.

The spermatozoon of $R$. sarba shares with other sparid species examined the presence of a satellite nuclear notch. Indeed, a similar structure has been described in the spermatozoa of six species (A. schelegeli, A. latus, P. major ,A. berda, S. aurat and P. bogaraveo ( Maricchiolo et al., 2010) .

The distribution of this feature in other sparids is uncertain, but it appears to be unique to the family and may be of systematic importance.

Within the family Sparidae, the location and shape of the nuclear notch differs between species. Generally in the sparids, this structure can be seen, in the nucleus, at the level of the proximal centriole (Gwo et al., 2004a, 2005; Maricchiolo et al., 2007). On the other hand, the nuclear notch in $R$. sarba sperm is located above the proximal centriole.

Within the family Sparidae, Gwo et al. (2004a) distinguished two sperm morphotypes based on the depth of nuclear fossa and symmetry of the head region. They mentioned that nuclear fossa is deep ( greater than one half of the nuclear diameter) in Sparinae species A. australis, A. berda, A. latus, A schlegeli, S. aurata, in P. major of the Pagrinae, in P. bogaraveo, in $R$. sarba (of the present study), in P. erythrinus, in $D$. cervinus, in D. sargus and in D. puntazzo, whereas it is shallow (less than half of the nuclear diameter) in $L$. rhomboides and A. probatocephus. Thus, both morphotypes which have seen in these species appear polyphyletic from weighted nucleotide analysis (Orrel et al., 2002). In these stage, the nuclear fossa of R.sarba spermatozoa is bell shaped, which is a similar to that reported in pagrus majir (Gwo et al., 2004a).

The present results provided only a few pieces needed to classify fish using spermatozoan morphology. The Perciformes is the largest and most diverse vertebrate order (Lauder and Liem, 1983). The spermatozoa of numerous Perciformes families need to be described in order to furnish the data needed to place Sparidae into a general fish classification on the basis of spermatozoan ultrastructure.

\section{Acknowledgments}

We deeply appreciate king Abdul-Aziz City for Science and Technology for supporting this research. Also, we thank King Fahd Medical Research Center, especially The Electronic Unit. This research was supported by a grant from king Abdul-Aziz City for Science and Technology under project T-T-10-0179

\section{References}

[1]. Baccetti, B. ; Burrini, A.G. ; Callaini, G. ; Gibertini, G. ; Mazzini, M. and Zerunian, S. (1984): Fish germinal cells I. Comparative spermatology of seven cyprinid species , Gamete Res. , 10: 373-396

[2]. Bruslè, S.( 1981): Ultrastructure of spermiogenesis in Liza aurata Risso, 1810 (Teleostei, Mugilidae). Cell Tissue Res. , 217: 415424

[3]. Cinquetti R, Dramis L (2003). Histological, histochemical, enzyme histochemical and ultrastructural investigations of the testis of Padogobius martensi between annual breeding seasons. J. Fish.Biol. 63: 1402-1442.

[4]. Christensen, M.S. ( 1978): Trophic relationships in juveniles of three species of sparid fishes in the South African marine littoral, Fish. Bull. 76:389- 40 .

[5]. Cosson, J. ; Billard, R. ; Cibert, C. ; Dreanno, C. and Suquet, M. (1999): Ionic factors regulating the motility of fish sperm. In: Gagnon, C. (Ed.), The Male Gamete: From Basic Science to Clinical Applications. Cache River Press, Vienna, IL, pp. $161-186$.

[6]. Grier, H. J. 1981. Cellular organization of the testis and spermatogenesis in fishes. Am. Zool. 21:345-357.

[7]. Grigorakis, K. ; Alexis, M.N. ; Taylor, K.D.A. and Hole, M. (2002): Comparison of wild and cultured gilthead sea bream (Sparus aurata); composition, appearance and seasonal variation._Int. J. Food. Sci. Tech. 37: 477-484

[8]. Gwo, J.-C., (1995): Spermatozoan ultrastructure of the teleost fish Acanthopagrus latus (Perciformes: Sparidae) with special reference to the basal body. J. Submicrosc. Cytol. Pathol. 27: 391-396. 
[9]. Gwo, J.-C. and Gwo, H.-H.( 1993): Spermatogenesis in the black porgy Acanthopagrus schlegeli (Teleostei: Perciformes: Sparidae), Mol. Reprod. Dev. , 36: 75-83.

[10]. Gwo, J.-C. ; Gwo, H.-H. and Chang, S.-L. (1993): The ultrastructure of the spermatozoon of the teleost fish Acanthopagrus schlegeli (Perciformes, Sparidae), J. Morphol. , 216: 29-33.

[11]. Gwo, J.C. ; Yang, W.T. ; Kuo, M. C. ; Takemura, A. and Cheng, H.Y. ( 2004a): Spermatozoal ultrastructures of two marine perciform teleost fishes, the goatfish, Paraupeneus spilurus (Mullidae) and the rabbitfish, Siganus fuscescens (Siganidae) from Taiwan. ,Tiss. Cell., 36: 63-69.

[12]. Gwo, J.-C. ; Kuo, M.-C.; Chiu, J.-Y. and Cheng, H.-Y. (2004 b): Ultrastructure of Pagrus major and Rhabdosargus sarba spermatozoa (Perciformes: Sparidae: Sparinae), Tiss. Cell. , 36: 141-147.

[13]. Gwo JC, Lin CY, Yang WL, Choud YC (2006). Ultrastructure of the sperm of blue sprat, Spratelloides gracilis; Teleostei, Clupeiformes, Clupeidae. Tissue Cell 38: 285-291.

[14]. Gwo, J.C. ; Chiu, J.Y. ; Lin, C.Y.; Su, Y. and Yu, S.L. ( 2005): Spermatozoal ultrastructure of four Sparidae fishes: Acanthopagrus berda, Acanthopagrus australis, Lagodon rhomboids and Archosargus probatocephus , Tiss. Cell., 37: 109-115.

[15]. Hara, M. and Okiyama, M.( 1998): An ultrastructural review of the spermatozoa of Japanese fishes , Bull. Ocean Res. Inst. Univ. Tokyo, 33: 1- 138 .

[16]. Jamieson, B.G.M.( 1991): Fish Evolution and Systematics: Evidence from Spermatozoa. Cambridge University Press, Cambridge, pp. 1-319

[17]. Jamieson, B.M.G. and Leung, L.K.P.( 1991): Introduction to fish spermatozoa and themicropyle. In. Fish evolution and systematics: Evidence from spermatozoa. Jamieson, B.M.G. (Ed). Cambridge University Press, Cambridge. 319 pp.

[18]. Jamieson , B.G.M. and Grier , H. j. (1993): Influencrs of phylogenetic position and fertilization biology on spermatozoa ultrastructure exemplified by exoooetoid and poeciliid fish, Hydrobiologia , 271:11-25.

[19]. Jamieson BGM (2009). Reproductive Biology and Phylogeny of Fishes (Agnathans and Bony Fishes), Part A. Sci. Pub. Enfield NH, USA. p. 788 .

[20]. Kato, K. ; Murata, O. ; Yamamoto, S. ; Miyashita, S. and Kumai, H.(2001): Viability, growth and external morphology of meioticand mitotic-gynogenetic diploids in red sea bream, Pagrus major, J. Appl. Ichthyol.,17: 97-103.

[21]. Lahnsteiner, F. and Patzner, R.A. ( 1995): Fine structure of spermatozoa of two marine teleost fishes, the red mullet, Mullus barbatus (Mullidae) and the white sea bream, Diplodus sargus (Sparidae), J. Submicrosc. Cytol. Pathol. , 27 (2): 259-266 .

[22]. Lahnsteiner, F. and Patzner, R.A. (1999): Characterization of spermatozoa and egg of rabbitfish , J. Fish Biol. , 55: 820-835

[23]. Lahnsteiner, F.; Patzner, R.A. and Weissman, T.( 1991): The fine structure of spermatozoa

[24]. of the grayling, Thymallus thymallus (Pisces, Teleostei), J.Submicrosc. Cytol.Pathol,27:259-266.

[25]. Mansour N. ; Lahnsteiner, F. and Patzner, C. A. (2002): The spermatozoon of the African catfish: fine structure, mobility, viability and behavior in seminal vesicle secretion, J. Fish .Biol., 60: 545-560.

[26]. Maricchiolo, G. ; Genovese, L. ; Laurà, R. ; Micale, V. and Muglia, U. (2007): Fine structure of gilthead sea bream (Sparus aurata Linnaeus, 1758) (Perciformes Sparidae), Histol. Histopathol., 22: 79-83.

[27]. Maricchioloa G. ; Lauràb, R ; Genovesea, L. ; Guerrerab, M.C. ; Micalea, V. and Mugliab, U. (2010): Fine structure of spermatozoa in the blackspot sea bream Pagellus bogaraveo (Brünnich, 1768) with some considerations about the centriolar complex , Tiss. Cell. , $42: 88-96$.

[28]. Mattel, C.(1970): Spermiogeneses comparee des Poissons. In: Baccetti, B. (Ed.), Comparative Spermatology. Academic Press, New York, pp. 55-70.

[29]. Mattei, X.( 1988): The flagellar apparatus of spermatozoa in fish. Ultrastructure and evolution, Biol. Cell. , 63, 151-158.

[30]. Mattei, X. (1991): Spermatozoon ultrastructure and its systematic implication in fish, Can. J. Zool., 69: 3038-3055

[31]. Medina, A. ; Megina, C. ; Abascal, F.J. and Calzada, A.( 2003): The sperm ultrastructure of Merluccius merluccius (Teleostei, Gadiformes): phylogenetic considerations, Acta Zool. , 84: 131-137.

[32]. Nelson JS (2006). Fishes of the World, 4th edition John Wiley and Sons, Inc., Hoboken, NJ, p. 601.

[33]. Nõbrega RH, Batlouni SR, França LR (2009). An overview of functional and stereological evaluation of spermatogenesis and germ cell transplantation in fish. Fish Physiol. Biochem. 35: 197-206

[34]. Orrel, T.M. ; Kent, E. ; Carpenter, K.E. ; Musik, J.A. and Graves, J.E., (2002): Phylogenetic and biogeographic analysis of the Sparidae (Perciformes: Percoidei) from cytochrome b sequences, Copeia , 3: 618-631.

[35]. Quagio-Grassiotto , I. ; Negrao. J. N. C. ; Carvalho E. D. and Foresti , F. (2001): Ultrastructure of spermatogenic cells and spermatozoa in Hoplias malabaricus (Teleostei, Characiformes, Erythrinidae), J. Fish Biol. ,59: 1494-1502.

[36]. Quagio-Grassiotto, I. ; Gameiro, M. C. ; Schneider, T. ; Malabarba, L. R. and Oliveira, C. (2003): Spermiogenesis and spermatozoa ultrastructure in five species of the Curimatide with some considerations on spermatozoal ultrastructure in the Characiformes, Neotropical Ichthyol. , 1: 35-45.

[37]. Shahin ,A. A. B.( 2006a): Spermatogenesis and spermatozoon ultrastructure in the Nile Pebblyfish Alestes dentex (Teleostei: Characiformes: Alestidae) in Egipt, World J. Zool. , 1: 1-16.

[38]. Shahin, A. A. B. (2006b): Semicystic spermatogenesis and biflagellate spermatozoon ultrastructure in the Nile electric catfish Malapterurus electricus (Teleostei: Siluriformes:Malapteruridae), Acta Zool. , 87: 215-22.

[39]. Taddei, A.R. ; Barbato, F. ; Abelli, L. ; Canese, S. ; Moretti, F. ; Rana, K.J. ; Fausto, A.M. and Mazzini, M.( 2001): Is cryopreservation a homogeneous process? Ultrastructure and motility of untreated, prefreezing, and postthawed spermatozoa of Diplodus puntazzo (Cetti), Cryobiology, $42: 244-255$

[40]. Zaki MI, Negm RK, El-agamy A, Awad GS (2005). Ultrastructure of male germ cells and character of spermatozoa in boops boops (Family Sparidae) in Alexandria coast, Egypt. Egyp. J. Aquat Res. 31(2): 293-313. 